\title{
Analysis of Traumatic Brain Injuries Sustained by Occupants in Japanese Brand Car Crashes in the US
}

\author{
Jacobo Antona-Makoshi ${ }^{1)}$ Koji Mikami ${ }^{1)}$ Mats Lindkvist ${ }^{2)}$ Johan Davidsson ${ }^{3)}$ \\ 1) Japan Automobile Research Insitute \\ 2530 Karima, Tsukuba, Ibaraki, 305-0822, Japan (E-mail: ajacobo@jsae.or.jp) \\ 2) Umeå University, SE-901 87, Umeå, Sweden \\ 3) Chalmers University of Technology, SE-412 96, Gothenburg, Sweden.
}

Received on August 9, 2017

\begin{abstract}
This study estimates, by means of an analysis of accident data from the US, the incidence and risk of car crash related traumatic brain injuries for occupants in Japanese brand cars. The study incorporated crash type, crash severity, car model year, belt use and the victim's age and sex. Concussion risk was the highest among all brain injury categories for all crash types and severities; females were at higher risks than males. When concussions were excluded, Subdural Haemorrhages, Intracranial Haemorrhages and Sub-Arachnoid Haemorrhages comprised the most frequent injury categories. Elderly occupants were at considerably higher risks than non-elderly for these bleeding injuries.
\end{abstract}

KEY WORDS: safety, injury database, accident analysis, traumatic brain injury, concussion, elderly, female [C1]

\section{Introduction}

Half of the 1.3 million annual traffic related deaths and the 50 million traffic related injuries worldwide are due to Traumatic Brain Injuries (TBIs) ${ }^{(1)}$. Vehicle occupants comprise the largest group of road traffic deaths by road user type in most highincome countries ${ }^{(1)}$. TBIs are the main cause of death and severe injuries amongst most vehicle crash types and population groups; young adults and the elderly are at higher risks than mature adults $(2,3)$ and females are at higher risks than males ${ }^{(4)}$. These cited studies suggest that despite the ever-improving vehicle occupant protection ${ }^{(5)}$, TBI prevention strategies must be assigned top priority.

TBI prevention strategies commonly target at the reduction of life-threatening head injuries that predominantly occur in high severity crashes ${ }^{(6)}$. These strategies have proven insufficient to achieve significant reductions of TBIs risks ${ }^{(7)}$. Mild and moderate TBIs, which are mainly concussions, have traditionally gained less attention in the development of prevention strategies. However, recent real-world data analysis has shown that concussions account for $60 \%$ of all head injuries in car crashes ${ }^{(8)}$. In addition, numerous studies have shown that a single concussion can lead to long term consequences and that $30 \%$ of concussion victims may suffer persistent cognitive, physical or psychosocial impairment usually known as Chronic Concussion Syndrome ${ }^{(9)}$. Hence, in addition to life-threatening injuries, updated TBI prevention strategies should incorporate assessments of concussion injury risk. For the development of such prevention strategies, occupant factors and injury specificity need to be considered.

The US National Automotive Sampling System Crashworthiness Data System (NASS-CDS) is a publicly available US nationwide Motor Vehicle Crash (MVC) data collection program developed and maintained by the National
Highway Traffic Safety Administration (NHTSA) ${ }^{(10)}$. NASSCDS is a probability sample survey of towed-away and policereported MVCs across the country that allows for national estimates on crash, vehicle, and occupant characteristics. The main purpose of NASS-CDS is to produce statistics on MVCs that facilitate the development and the evaluation of motor vehicle safety standards in the US ${ }^{(10)}$.

Japan is a highly motorized country and has one of the largest and most prominent auto industries in the world. Japanese roads are within the safest in the world by population ${ }^{(11)}$ and many Japanese brands are well known for their outstanding high performance on most safety evaluation programs ${ }^{(12)}$. Despite this, both Japan and its auto industry still face a number of challenges in traffic safety. Some of these challenges are common to authorities and auto industries in other countries, e.g. the persistence of TBIs as the main source of fatal and severe injuries (13). Some of the challenges are unique to Japan, e.g. having the most aged population in the world, which reflects in the elderly dominating the statistics on fatal and severe traffic related injuries (13)

Regrettably, no publicly available accident database like NASS-CDS exists in Japan. This imposes difficulties for the efficient development of TBI prevention strategies for Japan. The presence of Japanese cars in the NASS-CDS database is however large and an analysis, which to the best knowledge of the authors does not exist, can provide information useful for the design of TBI prevention strategies for Japan. Especially so when information obtained in studies on traffic environment, and occupant characteristics in Japan are considered in the interpretation of the obtained results ${ }^{(14,15)}$. In addition, the entire global population at risk may benefit from the development of even safer Japanese cars.

The ultimate goal of this study is to support Japanese policy makers, industry, academy, and related research institutions in the 
development of TBI-specific strategies. The specific aim is to estimate, by means of an analysis of NASS-CDS data, the incidence and risk of all moderate-to-unsurvivable TBIs sustained by occupants in Japanese brand car crashes in the US, and to analyze the data considering crash type, crash severity, car model year, belt use and the victim's age and sex.

\section{Methods}

NASS-CDS cases from years 2001 to 2015 were analyzed to estimate the incidence and risk of TBIs sustained by occupants of Japanese brand car crashes. First, a descriptive analysis was conducted to estimate the incidence and risks for different TBI categories by crash type and belt use. Second, the logistic regression method was applied to model the effects of car model year, crash severity, occupant's sex and age on the odds of sustaining the most relevant injuries identified, while controlling for other factors such as crash type or belt use. Detailed descriptions of the inclusion criteria, the injury classification and the data analysis methods applied in this study follow.

\subsection{Inclusion Criteria}

The following inclusion criteria were applied in this study:

- Crash year 2001-2015

- Frontal, side, rear, and rollover crash types as defined by highest area of vehicle damage (GAD1) and rollover variables

- Vehicle model year 2001-2015

- Light vehicles, including passenger cars, pick-ups and minivans

- Japanese brand vehicles, including 13 brands

- Occupant age 15 or higher

- Belted and unbelted occupants

- Non-ejected occupants

- Occupants with reported injury or fatality status.

\subsection{Injury Definitions}

Injuries in NASS-CDS are reported according to the Abbreviated Injury Scale (AIS), which is an anatomically based scoring system that classifies injuries ${ }^{(16)}$. The following brain injury categories were adopted using the AIS-90/98 scale:

- Concussion: AIS2-3 injuries reported as Cerebral Concussion, as Awake Post Resuscitation, as Level of Consciousness, or as Length of Unconsciousness.

- Contusion: AIS3-5 injuries reported as contusions in the brain.

- Diffuse Axonal Injury (DAI): AIS4-5 injuries reported as white matter shearing in the brain, as Level of Consciousness, or as Length of Unconsciousness.

- Epidural Haemorrhage (EDH): AIS4-5 injuries reported as epidural or extradural haematoma/haemorrhage in the brain.

- Sub-Dural Haemorrhage (SDH): AIS4-5 injuries reported as subdural haematoma/haemorrhage in the brain.

- Sub-Arachnoid Haemorrhage (SAH): AIS3 injuries reported as subarachnoid or subpial haemorrhage in the brain.

- Intracranial Haemorrhage (ICH): AIS4-5 injuries reported as intracerebral, intracerebellar or intraventricular haematoma/haemorrhage.
- Brainstem Injury: AIS5-6 injuries reported as injuries to the brainstem regardless of injury type.

- BrainOthers: All AIS3-5 injuries to the brain not included in any of the above categories (e.g. pituitary injury, swelling, infarction, penetration, and injuries in the cerebrum or the cerebellum no further specified).

\subsection{Descriptive Analysis}

Incidence of a particular injury was defined as the number of occupants who sustained that particular injury as their highest severity injury (MAIS). The risk that an occupant experienced a particular injury was calculated as the number of occupants with that particular injury divided by the number of occupants with known injury status ${ }^{(8)}$. SAS Enterprise Guide version 7.1 (SAS Institute Inc.) software was utilized to analyze the data. Standard errors (SE) were calculated by using the SAS survey procedure (SURVEYFREQ) that accounts for NASS-CDS variables for stratification, clustering, and sampling weights ${ }^{(17)}$.

\subsection{Odds Ratio Analysis}

This part of the study was limited to belted occupants in frontal cases from which crash severity as represented by delta-V (DVTOTAL) was available. The SAS logistic regression procedure (SURVEYLOGISTIC) was applied to model the effects of crash severity, occupant's sex and age on the odds for an occupant to sustain the most relevant injuries identified. Each of these injury categories was considered as a dichotomous categorical variable equal to one for occupants with the injury and zero otherwise.

Crash severity was modeled as a continuous variable using delta-V. Sex and Age were considered as dichotomous variables (Female vs Male; Elderly vs respect to Non-elderly). Three car model year groups (2001-2004, 2005-2010, 2011-2015) were considered according to years in which changes of safety regulations or assessment programs may have influenced the safety performance of vehicles. Model year group 2001-2004 represented the first generation of vehicles with depowered airbags. Model year group 2005-2010 complied with FMVSS301 updates and included the first generations of consumer ratings such as the IIHS top safety pick awards. Model year group 20112015 complied with the enhanced US-NCAP.

\section{Results}

Using the inclusion criteria on the NASS-CDS data resulted in a dataset consisting of 15,969 raw occupants. Applying the weighting factors provided a sample of 6,627,487 occupants.

Table 1 shows the annual average (AVE) number of weighted occupants, their percent distribution, and the belt use rates by occupant's sex and three age groups (Young: 15-34, Adult: 35-64, and Elderly:65+).

More than half (55.9\%) of the occupants were females. For both sexes, the Young group was overrepresented, followed by the Adult and the Elderly groups. Elderly occupants represented a $9.3 \%$ of the total sample. Overall belt use rate was 0.81 , with lower rates in males $(0.76)$ than in females $(0.84)$. Belt rates were 
higher in Elderly males (0.87) than in younger Males. Belt use was equally high in all ages for female occupants.

Table 1. Data Sample

\begin{tabular}{|c|c|c|c|c|}
\hline \multirow{4}{*}{ Sex } & $\begin{array}{c}\text { Age } \\
\text { Group }\end{array}$ & $\begin{array}{c}\text { Weighted } \\
\text { Occupants }\end{array}$ & $\begin{array}{c}\text { \% of } \\
\text { Occupants }\end{array}$ & $\begin{array}{c}\text { Belt Use } \\
\text { Rate }\end{array}$ \\
\hline \multirow{4}{*}{ Female } & Young & 133,632 & 30.2 & 0.84 \\
\cline { 2 - 5 } & Adult & 91,804 & 20.8 & 0.83 \\
\cline { 2 - 5 } & Elderly & 21,730 & 4.9 & 0.84 \\
\cline { 2 - 5 } & Total (F) & 247,166 & 55.9 & 0.84 \\
\hline \multirow{4}{*}{ Male } & Young & 107,013 & 24.2 & 0.76 \\
\cline { 2 - 5 } & Adult & 68,235 & 15.4 & 0.74 \\
\cline { 2 - 5 } & Elderly & 19,419 & 4.4 & 0.87 \\
\cline { 2 - 5 } & Total (M) & 194,667 & 44.1 & 0.76 \\
\hline \multicolumn{2}{|c|}{ Total (F+M) } & 441,832 & 100 & 0.81 \\
\hline
\end{tabular}

\subsection{Brain Injury Category by Injury Severity}

Table 2 shows the annual incidence of MAIS2+ TBIs by injury category and injury severity. A total of 9,025 $\pm 2,245$ occupants with concussion were estimated, which accounts for $86.3 \%$ of the $10,449 \pm 2,760$ occupants with MAIS2+ brain injuries. The large majority of these concussions (99.5\%) were of MAIS2 severity. Excluding concussions, the most frequent injury categories were SDH (338 \pm 65), followed by ICH (288 \pm 118 ), SAH (280 \pm 109), Brainstem (130 \pm 37), DAI (128 \pm 63$)$, and Contusion (107 \pm 49$)$.

Table 2. Annual Incidence (AVE \pm SE) of MAIS2+ TBIs by injury severity

\begin{tabular}{|c|c|c|c|c|c|c|}
\hline \multirow{2}{*}{$\begin{array}{c}\text { No. of } \\
\text { Occupants }\end{array}$} & \multicolumn{5}{|c|}{ MAIS brain } & \multirow{2}{*}{ Total } \\
\hline & 2 & 3 & 4 & 5 & 6 & \\
\hline Concussion & $\begin{array}{c}8,987 \\
\pm 2,226\end{array}$ & $\begin{array}{c}37 \\
\pm 18\end{array}$ & - & & & $\begin{array}{r}9,025 \\
\pm 2,245\end{array}$ \\
\hline Contusion & - & $\begin{array}{l}104 \\
\pm 46\end{array}$ & $\begin{array}{c}2 \\
\pm 2\end{array}$ & $\begin{array}{c}1 \\
\pm 1\end{array}$ & - & $\begin{array}{l}107 \\
\pm 49\end{array}$ \\
\hline DAI & - & - & $\begin{array}{c}16 \\
\pm 13 \\
\end{array}$ & $\begin{array}{l}112 \\
\pm 50 \\
\end{array}$ & - & $\begin{array}{l}128 \\
\pm 63 \\
\end{array}$ \\
\hline Brainstem & - & - & - & $\begin{array}{c}68 \\
\pm 22 \\
\end{array}$ & $\begin{array}{c}62 \\
\pm 15 \\
\end{array}$ & $\begin{array}{l}130 \\
\pm 37 \\
\end{array}$ \\
\hline $\mathrm{SDH}$ & - & - & $\begin{array}{l}269 \\
\pm 41 \\
\end{array}$ & $\begin{array}{c}69 \\
\pm 24 \\
\end{array}$ & - & $\begin{array}{l}338 \\
\pm 65 \\
\end{array}$ \\
\hline $\mathrm{SAH}$ & - & $\begin{array}{c}280 \\
\pm 109 \\
\end{array}$ & - & - & - & $\begin{array}{c}280 \\
\pm 109 \\
\end{array}$ \\
\hline $\mathrm{EDH}$ & - & - & $\begin{array}{c}22 \\
\pm 12 \\
\end{array}$ & $\begin{array}{c}6 \\
\pm 4 \\
\end{array}$ & - & $\begin{array}{c}27 \\
\pm 16 \\
\end{array}$ \\
\hline $\mathrm{ICH}$ & - & - & $\begin{array}{l}204 \\
\pm 79\end{array}$ & $\begin{array}{c}84 \\
\pm 39 \\
\end{array}$ & - & $\begin{array}{c}288 \\
\pm 118 \\
\end{array}$ \\
\hline Others & - & $\begin{array}{c}79 \\
\pm 34\end{array}$ & $\begin{array}{c}33 \\
\pm 15\end{array}$ & $\begin{array}{l}14 \\
\pm 9\end{array}$ & - & $\begin{array}{l}126 \\
\pm 58\end{array}$ \\
\hline Total & $\begin{array}{c}8,987 \\
\pm 2,226 \\
\end{array}$ & $\begin{array}{c}500 \\
\pm 207 \\
\end{array}$ & $\begin{array}{c}547 \\
\pm 163 \\
\end{array}$ & $\begin{array}{c}354 \\
\pm 149 \\
\end{array}$ & $\begin{array}{c}62 \\
\pm 15 \\
\end{array}$ & $\begin{array}{l}10,449 \\
\pm 2,760 \\
\end{array}$ \\
\hline
\end{tabular}

\subsection{Brain Injury Category by Crash Type}

Table 3 and Table 4 show the annual incidence and risks for occupants with MAIS2+ TBIs by injury category and crash type. The sample was dominated by occupants whose vehicle had the greatest damage in the Frontal area (205,143 \pm 26,913 occupants), followed by the Side (101,879 $\pm 16,006$ occupants), the Rear (28,045 \pm 3,588 occupants) and Rollover cases (13,066 \pm 1,750 occupants). The incidence and risk for concussions were the highest among all crash types. Excluding concussions, SDH comprised the most frequent injury category in frontal crashes (202 \pm 38 occupants, $0.10 \pm 0.02 \%$ risk) followed by SAH (190 \pm 98 occupants, $0.09 \pm 0.05 \%$ risk). In side crashes, ICH was the most common category (117 \pm 59 occupants, $0.12 \pm 0.06 \%$ risk) followed by DAI ( $84 \pm 50$ occupants, $0.08 \pm 0.05 \%$ risk). In rear crashes, SDH was the most relevant injury category (55 \pm 33 occupants, $0.2 \pm 0.12 \%$ risk). In rollovers, contusion was the most relevant category (64 \pm 39 occupants, $0.49 \pm 0.30 \%$ risk).

Table 3. Annual Incidence (AVE \pm SE) of MAIS2+ TBIs by crash type

\begin{tabular}{|l|c|c|c|c|}
\hline $\begin{array}{l}\text { No. of } \\
\text { Occupants }\end{array}$ & Frontal & Side & Rear & Rollover \\
\hline $\begin{array}{l}\text { Known } \\
\text { injury status }\end{array}$ & $\begin{array}{c}205,143 \\
\pm 26,913\end{array}$ & $\begin{array}{l}101,879 \\
\pm 16,006\end{array}$ & $\begin{array}{c}28,045 \\
\pm 3,588\end{array}$ & $\begin{array}{c}13,066 \\
\pm 1,750\end{array}$ \\
\hline Concussion & $3,815 \pm 905$ & $2,989 \pm 1,265$ & $811 \pm 440$ & $671 \pm 201$ \\
\hline Contusion & $19 \pm 9$ & $20 \pm 16$ & - & $64 \pm 39$ \\
\hline DAI & $19 \pm 10$ & $84 \pm 50$ & $12 \pm 11$ & $7 \pm 5$ \\
\hline Brainstem & $50 \pm 16$ & $46 \pm 15$ & $1 \pm 1$ & $8 \pm 4$ \\
\hline SDH & $202 \pm 38$ & $48 \pm 15$ & $55 \pm 33$ & $16 \pm 10$ \\
\hline SAH & $190 \pm 98$ & $32 \pm 13$ & $18 \pm 12$ & $25 \pm 5$ \\
\hline EDH & $17 \pm 11$ & $9 \pm 6$ & - & - \\
\hline ICH & $89 \pm 31$ & $117 \pm 59$ & $4 \pm 2$ & $27 \pm 13$ \\
\hline Others & $35 \pm 12$ & $53 \pm 25$ & - & $23 \pm 17$ \\
\hline
\end{tabular}

Table 4. MAIS2+ TBI risk (AVE \pm SE) by crash type

\begin{tabular}{|l|c|c|c|c|}
\hline TBI risk (\%) & Frontal & Side & Rear & Rollover \\
\hline Concussion & $1.86 \pm 0.44$ & $2.93 \pm 1.24$ & $2.89 \pm 1.57$ & $5.14 \pm 1.54$ \\
\hline Contusion & $0.01 \pm 0.00$ & $0.02 \pm 0.02$ & - & $0.49 \pm 0.30$ \\
\hline DAI & $0.01 \pm 0.00$ & $0.08 \pm 0.05$ & $0.04 \pm 0.04$ & $0.05 \pm 0.04$ \\
\hline Brainstem & $0.02 \pm 0.01$ & $0.05 \pm 0.01$ & - & $0.06 \pm 0.03$ \\
\hline SDH & $0.10 \pm 0.02$ & $0.05 \pm 0.01$ & $0.2 \pm 0.12$ & $0.13 \pm 0.08$ \\
\hline SAH & $0.09 \pm 0.05$ & $0.03 \pm 0.01$ & $0.06 \pm 0.04$ & $0.19 \pm 0.04$ \\
\hline EDH & $0.01 \pm 0.01$ & $0.01 \pm 0.01$ & - & - \\
\hline ICH & $0.04 \pm 0.02$ & $0.12 \pm 0.06$ & $0.01 \pm 0.01$ & $0.21 \pm 0.10$ \\
\hline Others & $0.02 \pm 0.01$ & $0.05 \pm 0.02$ & - & $0.17 \pm 0.13$ \\
\hline
\end{tabular}




\subsection{Effect of Belt Use on Brain Injury Risk}

The effect of belt use on MAIS3+ TBI risk and on concussion risk is presented in Fig.1 and Fig.2, respectively. SE is shown by bars. Unbelted occupants were at higher risks than belted occupants for all brain injury categories, including concussions.

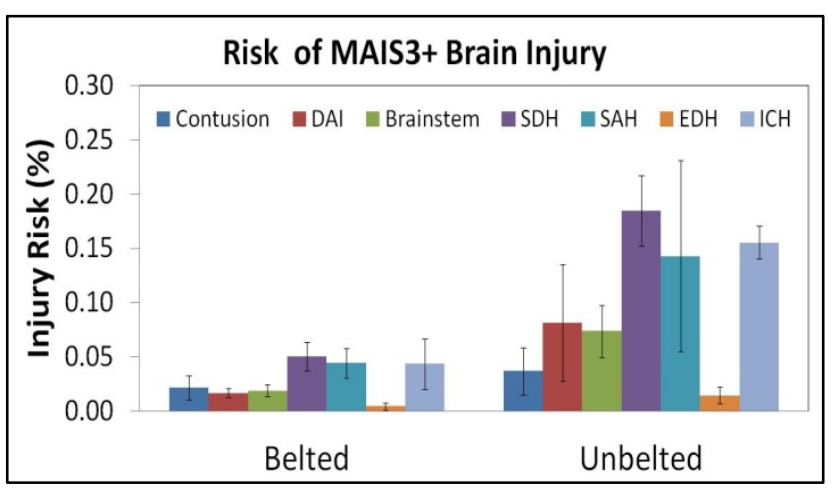

Fig.1 Effect of Belt Use on MAIS3+ TBI risk

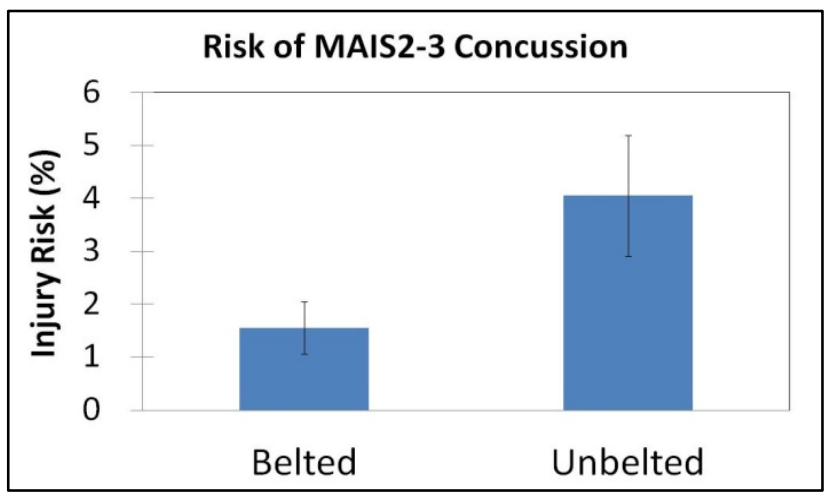

Fig.2 Effect of Belt Use on Concussion risk

3.4. Odds Ratio Analysis for Concussion and Bleeding injuries

Restricting the sample to belted occupants in frontal crashes with known delta- $\mathrm{V}$ resulted in a dataset containing a total of 1,583,190 weighted occupants from which 19,444 sustained a concussion and 2,420 sustained a bleeding injury (including SDH, ICH and ASH).

Table 5 summarizes the results from applying the odds ratio analysis to concussions. The p-values in the last column show that delta-V $(\mathrm{p}=0.001)$, sex $(\mathrm{p}=0.032)$ and age group $(\mathrm{p}=0.004)$ were all significant contributors to predict the probability of concussion at the $95 \%$ confidence level. Car model year group was not significant. The odds ratio point estimates in the second column indicate that, after adjusting for the effects of age and delta- $\mathrm{V}$, a belted female occupant involved in a frontal crash with a modern (2001+) Japanese car is estimated to be 1.665 times more likely to sustain a concussion than a belted male occupant.
Table 5. Odds Ratio Estimates for Concussion (Crash Year 200115, Model Year 2001-15, Japanese brand, Non-ejected, Age 15+, Belted, Frontal)

\begin{tabular}{|l|c|c|c|c|}
\hline \multicolumn{1}{|c|}{ Effect } & \multicolumn{1}{|c|}{$\begin{array}{c}\text { Point } \\
\text { Estimate }\end{array}$} & \multicolumn{2}{c|}{$\begin{array}{c}\text { 95\% Conf. } \\
\text { Limits }\end{array}$} & p-value \\
\hline delta-V & 1.043 & 1.020 & 1.066 & 0.001 \\
\hline Sex (Female vs Male) & 1.665 & 1.050 & 2.640 & 0.032 \\
\hline Elderly (65+ vs 15-64) & 0.328 & 0.164 & 0.655 & 0.004 \\
\hline $\begin{array}{l}\text { Model Year (2001/04 } \\
\text { vs 2011/15) }\end{array}$ & 0.430 & 0.122 & 1.512 & 0.091 \\
\hline $\begin{array}{l}\text { Model Year (2005/10 } \\
\text { vs 2011/15) }\end{array}$ & 0.821 & 0.204 & 3.305 & 0.646 \\
\hline
\end{tabular}

Table 6 summarizes the results from applying odds ratio analysis to bleeding injury. The p-values in the last column show that delta- $\mathrm{V}(\mathrm{p}<0.001)$ and age group $(\mathrm{p}=0.007)$ are significant contributors to predict the probability of bleeding injuries, but car model year group and sex are not. The odds ratio point estimates in the second column indicate that, after adjusting for the effects of delta- $\mathrm{V}$, a belted elderly occupant involved in a frontal crash with a modern (2001+) Japanese car is estimated to be 10.550 times more likely to sustain a Bleeding injury than a non-elderly belted adult (15-34).

Table 6. Odds Ratio Estimates for Bleeding Injuries (Crash Year 2001-15, Model Year 2001-15, Japanese brand, Non-ejected, Age 15+, Belted, Frontal)

\begin{tabular}{|l|c|c|c|c|}
\hline \multicolumn{1}{|c|}{ Effect } & $\begin{array}{c}\text { Point } \\
\text { Estimate }\end{array}$ & \multicolumn{2}{c|}{$\begin{array}{c}\text { 95\% Conf. } \\
\text { Limits }\end{array}$} & p-value \\
\hline delta-V & 1.111 & 1.055 & 1.171 & $<0.001$ \\
\hline Sex (Female vs Male) & 0.559 & 0.077 & 4.065 & 0.541 \\
\hline Elderly (65+ vs 15-64) & 10.550 & 2.070 & 53.767 & 0.007 \\
\hline $\begin{array}{l}\text { Model Year (2001/04 } \\
\text { vs 2011/15) }\end{array}$ & 0.591 & 0.049 & 7.069 & 0.995 \\
\hline $\begin{array}{l}\text { Model Year (2005/10 } \\
\text { vs 2011/15) }\end{array}$ & 0.346 & 0.028 & 4.305 & 0.324 \\
\hline
\end{tabular}

\section{Discussion}

This is the first public study that analyzes the incidence and risks sustained by occupants in US crashes with Japanese brand cars. Concussion risk was the highest among all crash types and crash severities. When concussions were excluded, SDH, ICH and $\mathrm{SAH}$ comprised the most common injury categories (Table 2). The trends found in this study for Japanese brand cars appear consistent with a study that applied a similar methodology and dataset and that included both Japanese and non Japanese car brands ${ }^{(18)}$. Hence, suggesting that both the trends for concussion 
injuries and bleeding injuries are not particular from Japanese car brands, but part of the general trends observed in NASS-CDS.

Female occupants were found to be at higher risks than male occupants of sustaining a concussion. More precisely, after controlling for crash severity and age, a belted female occupant was estimated to be 1.6 times more likely to sustain a concussion than a belted male occupant. This finding is in line with several sports medicine studies that have shown female athletes to be more likely to sustain a concussion than their male counterparts (19). Further research is needed to clarify if the injury risk differences identified are related to differences in how restraint systems perform due to different body size between males and female, or if the differences in risks are associated to more detailed inherent anatomical or physiological differences between sexes. Nevertheless, test methods that assess the risk of concussion in traffic crashes should be developed and implemented. These methods should account for the observation that concussions predominantly occur at low and moderate collision severities ${ }^{(8)}$ and may need to consider prioritization of females over males.

Elderly occupants were found to be at higher risks than nonelderly occupants of sustaining MAIS3+ brain injuries. A number of studies in the past have shown age to be an important risk factor for AIS3+ head injuries ${ }^{(20)}$. Furthermore, a detailed study based on NASS-CDS data from years 1993-2007 has shown that the effect of age was particularly high for extra-axial bleeding injuries (including SDH, SAH and EDH) ${ }^{(21,22)}$. The current study, although less detailed in terms of analysis of accompanying injuries, confirms that age is an important risk factor of bleeding injuries. The current study also suggests that this increase of bleeding injury risk in elderly persists in modern vehicles. In addition, this study found that concussion risk was lower in elderly than in non-elderly occupants. Hence, the results of past studies and the current call for the development of strategies that prioritize the prevention of bleeding injuries in all age groups, but particularly in the elderly. For this specific age group, bleeding injury prevention should be prioritized over concussion prevention.

\section{Limitations}

This study is based on a single database of vehicle crashes that occurred in the US. Not all vehicle crashes occurring in the US are included in the database. Weight factors have been used in the analysis carried out in this study to provide results that are deemed representative of US traffic environment, vehicle and occupant characteristics. However, these characteristics do not necessarily reflect those of Japan ${ }^{(14,15)}$. This limitation affects the applicability of this study in the development of strategies for the prevention of TBIs in Japan. Additional research that compares traffic crash data from Japan with the results presented in this study is needed.

Incidence of a particular injury was defined as the number of occupants who sustained that particular injury as their highest severity injury (MAIS). This method is common practice for prioritization purposes in the development of prevention strategies, which this study mainly targets at. However, particularly in TBIs of high injury severity, accompanying injuries are well known to affect the occupant's outcome. Incorporating all the brain injuries that an occupant sustains may allow refining and improving the effectiveness of the strategies developed ${ }^{(21,22)}$.

\section{Conclusion}

Annually, an estimation of 8,987 $\pm 2,226$ occupants sustained a moderate concussion in a Japanese brand car crash in the US, which accounts for $86 \%$ of all occupants with MAIS2+ brain injuries. For concussion injuries, female occupants were at higher risks than males and elderly occupants were at lower risks than non-elderly.

If the focus is limited to serious-to-unsurvivable severity (MAIS3+) injuries, the three most frequent brain injury categories found were subdural haemorrhage, intracranial haemorrhage and sub-arachnoid haemorrhage. For these particular types of bleeding injuries, elderly occupants were at considerably higher injury risk than non-elderly occupants.

This paper is partially based on a proceedings manuscript presented at the JSAE 2017 Annual Congress.

\section{References}

(1) World Health Organization: WHO global status report on road safety 2013: supporting a decade of action (2013).

(2) Bener, A. et al.: The pattern of traumatic brain injuries: a country undergoing rapid development. Brain injury, Vol. 24, No. 2, p. 74-80 (2010).

(3) Bruns, J.,Hauser, W. A.: The epidemiology of traumatic brain injury: a review. Epilepsia, Vol. 44, No. s10, p. 2-10 (2003).

(4) Bose, D. et al.: Vulnerability of female drivers involved in motor vehicle crashes: an analysis of US population at risk. American journal of public health, Vol. 101, No. 12, p. 2368-2373 (2011).

(5) NHTSA: Traffic Safety Facts 2011 (2012)

(6) NHTSA: New Car Assessment Program. Federal Register, Vol. 73, No. 134 (2008)

(7) Eigen, A. M.,Martin, P. G.: Identification of real world injury patterns in aid of dummy development. Proceedings of 19th ESV Conference, p. 05-0219 (2005). 
(8) Viano, D. C.,Parenteau, C. S.: Concussion, diffuse axonal injury and AIS4+ head injury in motor vehicle crashes. Traffic injury prevention, Vol. 16, No. 8, p. 747-753 (2015).

(9) Carroll, L. J. et al.: Systematic review of the prognosis after mild traumatic brain injury in adults: cognitive, psychiatric, and mortality outcomes: results of the International Collaboration on Mild TBI Prognosis. Archives of physical medicine and rehabilitation, Vol. 95, No. 3, p. 152-173 (2014).

(10) Zhang, F.,Chen, C.-L.: NASS-CDS: sample design and weights (2013).

(11) Oguchi, T.: Achieving safe road traffic-the experience in Japan. IATSS Research, Vol. 39, No. 2, p. 110-116 (2016).

(12) Zuby, D.: Consumer Safety Information Programs at IIHS. Proceedings of 24th ESV Conference (2015).

(13) Japanese Police. "Annual report on road traffic fatal accidents and traffic law enforcement violations [in Japanese]". http://www.npa.go.jp/toukei/index.htm\#koutsuu., (Accessed 2018 April 24).

(14) Hayakawa, H. et al.: Traffic accident statistics and risk perceptions in Japan and the United States. Accident Analysis \& Prevention, Vol. 32, No. 6, p. 827-835 (2000).

(15) Atchley, P. et al.: Cultural foundations of safety culture: A comparison of traffic safety culture in China, Japan and the United States. Transportation research part F: traffic psychology and behaviour, Vol. 26, p. 317-325 (2014).

(16) Gennarelli, T. A.,Wodzin, E.: AIS 2005: a contemporary injury scale. Injury, Vol. 37, No. 12, p. 1083-1091 (2006).

(17) Gorman, D. et al.: Morphomics of the talus. Stapp car crash journal, Vol. 60, p. 287-300 (2016).

(18) Antona-Makoshi, J. et al.: Accident analysis to support the development of strategies for the prevention of brain injuries in car crashes. Accident Analysis \& Prevention, Vol. 117, p. 98-105 (2018).

(19) Zuckerman, S. L. et al.: Epidemiology of Sports-Related Concussion in NCAA Athletes From 2009-2010 to 2013-2014 Incidence, Recurrence, and Mechanisms. The American journal of sports medicine, Vol. 43, No. 11, p. 2654-2662 (2015).

(20) Ridella, S. A. et al.: Age-related differences in AIS 3+ crash injury risk, types, causation and mechanisms. Proceedings of IRCOBI Conference (2012).

(21) Mallory, A. et al.: Subdural Hematoma and Aging: Crash Characteristics and Associated Injuries. Proceedings of 22nd ESV Conference (2011).

(22) Mallory, A.: Head injury and aging: the importance of bleeding injuries. Ann Adv Automot Med, Vol. 54, No. 5 (2010). 